\title{
Use of general practice, diagnostic investigations and hospital services before and after cancer diagnosis - a population-based nationwide registry study of 127,000 incident adult cancer patients
}

Karina Garnier Christensen*, Morten Fenger-Grøn, Kaare Rud Flarup and Peter Vedsted

\begin{abstract}
Background: Knowledge of patterns in cancer patients' health care utilisation around the time of diagnosis may guide health care resource allocation and provide important insights into this groups' demand for health care services. The health care need of patients with comorbid conditions far exceeds the oncology capacity and it is therefore important to elucidate the role of both primary and secondary care. The aim of this paper is to describe the use of health care services amongst incident cancer patients in Denmark one year before and one year after cancer diagnosis.
\end{abstract}

Methods: The present study is a national population-based case-control (1:10) registry study. All incident cancer patients $(n=127,210)$ diagnosed between 2001 and 2006 aged 40 years or older were identified in the Danish Cancer Registry. Data from national health registries were provided for all cancer patients and for 1,272,100 controls. Monthly consultation frequencies, monthly proportions of persons receiving health services and three-month incidence rate ratios for one year before and one year after the cancer diagnosis were calculated. Data were analysed separately for women and men.

Results: Three months before their diagnosis, cancer patients had twice as many general practitioner (GP) consultations, ten to eleven times more diagnostic investigations and five times more hospital contacts than the reference population. The demand for GP services peaked one month before diagnosis, the demand for diagnostic investigations one month after diagnosis and the number of hospital contacts three months after diagnosis. The proportion of cancer patients receiving each of these three types of health services remained more than 10\% above that of the reference population from two months before diagnosis until the end of the study period.

Conclusions: Cancer patients' health service utilisation rose dramatically three months before their diagnosis. This increase applied to all services in general throughout the first year after diagnosis and to the patients' use of hospital contacts in particular. Cancer patients' heightened demand for GP services one year after their diagnosis highlights the importance of close coordination and communication between the primary and the secondary healthcare sector.

Keywords: Cancer, General practice, Diagnostic, Hospital admission, Outpatient visit, Health services, Consultation, Registry study, Aftercare, Denmark

\footnotetext{
*Correspondence: k.christensen@alm.au.dk

The Research Unit for General Practice, Research Centre for Cancer Diagnosis in Primary Care (CaP), Aarhus University, Bartholins Allé 2, 8000, Aarhus C, Denmark
} 


\section{Background}

One main task of a well-organised healthcare system is to effectively diagnose and treat serious diseases in a way that optimises the prognosis. Studies on the diagnosis of cancer suggest that non-conclusive initial visits and a long waiting period for investigations to be performed are likely to delay the diagnosis $[1,2]$ which may have a negative effect on survival $[3,4]$. Up to 2020 , we expect to see a $20 \%$ increase in the incidence of cancer; a growth that may be attributed to demographic changes and advances in medicine which means that more citizens will be living with cancer [5]. In this context, more knowledge of cancer patients' patterns of demand for health care services before as well as after their diagnosis is critical to identifying possibilities for improving both patient pathways and health care resource allocation.

A major concern in Denmark is that cancer patients have a poorer survival than patients in other European countries [6]. This has partly been explained by delay in cancer diagnosis and treatment [3,4,7]. More detailed knowledge of cancer patients' health care resource demands and utilization patterns around the time of diagnosis may undoubtedly allow us to better organize health care supply and further shorten the time to cancer diagnosis, notably if particular health care utilizations patterns can be identified in large population-based cohorts. Data from such studies may prove even more valuable if combined with information on referral to diagnostic investigations and use of hospital services which would help us identify specific patterns of health care use rooted in current clinical or organizational inexpediencies. Such research would also serve the purpose of further substantiating or qualifying previous research. Apart from a comprehensive British survey which showed much variation in the number of consultations with cancer symptoms before hospital referral for suspected cancer [8], most previous studies have included fewer than 500 cancer patients and have suggested that before the time of diagnosis, cancer patients use their general practitioner (GP) less than controls $[9,10]$ with GP consultation frequencies peaking in the first month after diagnosis [11].

Once a cancer patient has been diagnosed and treatment has been initiated, cancer trajectories are very different. However, common for all cancers is the claimed lack of primary care involvement after discharge, which may be ascribed to patients being reluctant to go back to primary care and primary care not being there for the patients [12-16]. We therefore need a precise description of cancer patients' health care usage in primary and secondary care after their cancer diagnosis. Such detailed knowledge would be particularly instrumental in identifying their need for health care services in the period after discharge from hospital.
The aim of this study was to describe incident adult cancer patients' health service utilisation one year prior to and one year after their first cancer diagnosis.

\section{Methods}

\section{Study design and setting}

The present study was a population-based case-control registry study with a 1:10 age and gender matching. Data on health service utilisation were collected for a period spanning from one year before to one year after the date of cancer diagnosis. The date of diagnosis was extracted from the Danish Cancer Registry [17].

In Denmark, health care services are free and taxfinanced. Nearly all citizens (98\%) are registered with a particular general practice. GPs act as gatekeepers to most of the remaining health care providers and most cancer-specific investigations are performed in public hospitals after referral. Some diagnostic investigations (ultrasound and conventional x-ray), endoscopies and biopsies can also be made by private practising specialists. Although cancer treatment takes place in public hospitals which are in charge of the cancer patient's treatment until he or she is discharged, the cancer patient needs continuous primary health care and cooperation between the primary and the secondary sector is a cornerstone in a comprehensive, patient-centred approach. Furthermore, the number of patients with comorbid conditions and their health care need far exceed the oncology capacity. It is therefore important to establish knowledge on the present role of primary care.

\section{Study population}

Denmark operates comprehensive population-based registries that link information on each citizen by a unique personal registration number assigned to every Danish citizen upon birth. Using the Danish Cancer Registry launched in 1943, we identified those patients who were diagnosed with a malignant neoplasm with ICD10 codes C00 to C97, except C44 (non-malignant melanoma), between 1 January 2001 through 31 December 2006 and who had not been registered with any previous notifiable cancer diseases from 1943 onwards (the abovementioned ICD10 codes and B21, D06, D07.6, D09.0, D09.1, D30, D32, D33, D35.2, D35.3, D35.4, D37 - DD48, E34, N87, and O01) [18]. Patients who were 40 years or older were included, because at all ages women have higher GP consultation rates than men with a peak between ages 15 and 35 [19] which could have biased the data. We thereby captured more than $95 \%$ of all incident cancers. Until 1978, the Danish Cancer Registry did not contain ICD10 codes, but solely ICD7 codes, and 120 patients were therefore excluded because they had such previous ICD7-coded cancer diagnoses. Only patients registered with a date of birth and gender in the Central Population Registry were included. Patients were excluded 
if they moved to another country during the observation period around the date of diagnosis, or if they got a second cancer (except for metastases with ICD10 codes C76-C80 and recurrent cancers in the same organ) in the two-year period after their incident cancer diagnosis.

Using incidence density sampling [20], we matched each cancer patient on gender and date of birth with ten controls from a reference population not registered with a cancer diagnosis in the Danish Cancer Registry until two years after the index date. The index date was defined as the date of diagnosis of the case. Persons born in 1930 or before were age-matched on the year of their birth because the groups were small. Controls could be sampled as controls more than once for different cases, but only once for the same case. The use of incidence density sampling meant that a control could also later be included as a cancer case (after two years).

\section{Registry data}

Data regarding date and type of cancer diagnoses were retrieved from the Danish Cancer Registry. Statistics Denmark conducted data linkage to the National Health Insurance Service Registry, the National Patient Discharge Registry, the Central Population Registry, the Registry of Causes of Death as well as to sociodemographic and socioeconomic variables which were also provided by Statistics Denmark. Personal registration numbers were pseudomised by Statistics Denmark which hosted the data. Approval was obtained from the Danish Data Protection Agency (journal no. 2009-41-3471), whereas approval from the Danish Ethical Committee is not required for registry studies.

Data on primary and secondary health service utilisation were collected from 1 January 2000 through 31 December 2007. The study period spanned the period from one year before to one year after the cancer diagnosis. Data from the National Health Insurance Service Registry included the number of face-to-face consultations in general practice in daytime and out-of-hours including home visits. Data regarding diagnostic investigations comprised $x$-ray (performed by radiologists), ultrasound (performed by gynaecologists and surgeons), endoscopies (performed by otorhinolaryngologists, gynaecologists, internists, surgeons and GPs) and biopsies (performed by otorhinolaryngologists, ophthalmologists, dermatologists, gynaecologists, internists, surgeons, orthopaedic surgeons and GPs). Data from the National Patient Discharge Registry gave the number of somatic hospital admissions, outpatient visits and diagnostic investigations (x-ray, ultrasound, CAT scan, MRI scan, angiography, endoscopies and biopsies). Contacts for both discharged and non-discharged outpatients were included. Endoscopies included all endoscopies

Table 1 Categorisation and definition of sociodemographic and socioeconomic indicators

\begin{tabular}{|c|c|c|}
\hline $\begin{array}{l}\text { Demographic and } \\
\text { socioeconomic indicators }\end{array}$ & Categorisation & Definition \\
\hline \multirow[t]{3}{*}{ Age } & $40-59$ years & \multirow{3}{*}{$\begin{array}{l}\text { Age was calculated at the day of diagnosis for the cancer } \\
\text { patients. Controls were matched on age and were thus } \\
\text { in the same age group as their respective cases. }\end{array}$} \\
\hline & $60-79$ years & \\
\hline & $>80$ years & \\
\hline \multirow[t]{3}{*}{ Country of origin } & Danish & \multirow{3}{*}{$\begin{array}{l}\text { Western countries are defined as: } \\
\text { Nordic countries, European Union countries, Andorra, } \\
\text { Liechtenstein, Monaco, San Marino, Switzerland, } \\
\text { the Vatican State, Canada, USA, Australia, New Zealand. } \\
\text { Non-Western countries are all remaining countries. }\end{array}$} \\
\hline & Immigrant/descendant Western & \\
\hline & $\overline{\text { Immigrant/descendant non-Western }}$ & \\
\hline \multirow[t]{2}{*}{ Marital status } & Married & \multirow{2}{*}{$\begin{array}{l}\text { Married are persons living in civil union or being married. } \\
\text { Remaining persons belong to the not married category. }\end{array}$} \\
\hline & Not married & \\
\hline \multirow[t]{4}{*}{ Education } & Basic & $\begin{array}{l}\text { Highest attained education categorised according to } \\
\text { the International Standard Classification of Education (ISCED). } \\
\text { Basic: Primary and lower secondary, 0-10 years. }\end{array}$ \\
\hline & Short & $\begin{array}{l}\text { Short: Upper secondary and post-secondary non-tertiary, } \\
11-15 \text { years. }\end{array}$ \\
\hline & Long & Long: Tertiary and advanced research programmes, $>15$ years. \\
\hline & Unknown & \\
\hline \multirow[t]{4}{*}{ Labour market affiliation } & Working & \multirow[t]{4}{*}{ Based on main employment during the preceding 12 months } \\
\hline & Unemployed & \\
\hline & Retired & \\
\hline & Leave and other & \\
\hline \multirow[t]{3}{*}{ Income } & Lowest $20 \%$ & \multirow{3}{*}{$\begin{array}{l}\text { Taxable income during the preceding } 12 \text { months using } \\
\text { the OECD-modified scale. }\end{array}$} \\
\hline & Middle 50\% & \\
\hline & Highest 30\% & \\
\hline
\end{tabular}


performed through natural body orifices only. Biopsies comprised all procedure codes containing the word biopsy in the descriptive text. For all variables from the National Patient Discharge Registry, only one event per category was included per day due to the complexity of the registrations in this registry. Age, gender and country of residence were obtained from the Central Population Registry, while the date of death was obtained from the Registry of Causes of Death.

The demographic and socioeconomic variables included country of origin, marital status, taxable income using the OECD-modified scale [21], highest attained education categorised according to the International Standard Classification of Education (ISCED) [22], and labour market affiliation. Data were retrieved for the year of the diagnosis or index date, except for country of origin where the latest registered value was selected due to inconsistencies in the registrations. See Table 1 for definition and categorisation of these variables.

\section{Outcome variables}

The outcome measure was the incidence rate of health services received per month and per three months one year before and one year after diagnosis. The index date (date of cases' cancer diagnoses) was contained in the month before the diagnosis. The proportion of persons receiving health services was calculated per month. Health services were collated into three groups: GP face-to-face consultations (daytime and out-of-hours), diagnostic investigations (primary and secondary sector) and hospital contacts.

\section{Analysis}

The date of consultation provided by the National Health Insurance Service Registry was given as a week number which was converted into a date in order to be able to calculate the interval from the diagnostic date to the date at which the health care service was provided. A negative binomial model was applied for the calculation of estimates

Table 2 Characteristics of the reference population and the cancer patients

\begin{tabular}{|c|c|c|c|c|c|c|c|c|}
\hline \multirow[b]{3}{*}{ Total (n (\%)) } & \multicolumn{4}{|c|}{ Women } & \multicolumn{4}{|c|}{ Men } \\
\hline & \multicolumn{2}{|c|}{ References } & \multicolumn{2}{|c|}{ Patients } & \multicolumn{2}{|c|}{ References } & \multicolumn{2}{|c|}{ Patients } \\
\hline & 633,620 & 100.0 & 63,362 & 100.0 & 638,480 & 100.0 & 63,848 & 100.0 \\
\hline \multicolumn{9}{|l|}{ Age (years) } \\
\hline $40-59$ & 193,210 & 30.5 & 19,321 & 30.5 & 144,390 & 22.6 & 14,439 & 22.6 \\
\hline $60-79$ & 319,440 & 50.4 & 31,944 & 50.4 & 387,190 & 60.6 & 38,719 & 60.6 \\
\hline $80+$ & 120,970 & 19.1 & 12,097 & 19.1 & 106,900 & 16.7 & 10,690 & 16.7 \\
\hline \multicolumn{9}{|l|}{ Country of origin } \\
\hline Danish & 603,303 & 95.2 & 60,881 & 96.1 & 612,551 & 95.9 & 61,698 & 96.6 \\
\hline Immigrant/descendant Western country & 17,723 & 2.8 & 1,652 & 2.6 & 13,396 & 2.1 & 1,281 & 2.0 \\
\hline Immigrant/descendant non-Western country & 12,444 & 2.0 & 829 & 1.3 & 12,308 & 1.9 & 867 & 1.4 \\
\hline \multicolumn{9}{|l|}{ Marital status } \\
\hline Married & 322,777 & 50.9 & 30,971 & 48.9 & 435,587 & 68.2 & 42,116 & 66.0 \\
\hline Not married & 310,843 & 49.1 & 32,391 & 51.1 & 202,893 & 31.8 & 21,732 & 34.0 \\
\hline \multicolumn{9}{|l|}{ Education } \\
\hline Basic & 279,425 & 44.1 & 28,461 & 44.9 & 228,450 & 35.8 & 23,319 & 36.5 \\
\hline Short & 185,337 & 29.3 & 18,624 & 29.4 & 252,794 & 39.6 & 25,580 & 40.1 \\
\hline Long & 81,025 & 12.8 & 7,777 & 12.3 & 84,125 & 13.2 & 7,640 & 12.0 \\
\hline Unknown & 87,833 & 13.9 & 8,500 & 13.4 & 73,111 & 11.5 & 7,309 & 11.4 \\
\hline \multicolumn{9}{|l|}{ Labour market affiliation } \\
\hline Working & 185,897 & 29.3 & 17,886 & 28.2 & 196,051 & 30.7 & 17,741 & 27.8 \\
\hline Unemployed & 19,256 & 3.0 & 1,972 & 3.1 & 13,234 & 2.1 & 1,536 & 2.4 \\
\hline Retired & 419,395 & 66.2 & 42,636 & 67.3 & 424,694 & 66.5 & 44,043 & 69.0 \\
\hline Leave and other & 8,898 & 1.4 & 868 & 1.4 & 4,255 & 0.7 & 522 & 0.8 \\
\hline \multicolumn{9}{|l|}{ Income } \\
\hline Low & 130,388 & 20.6 & 13,129 & 20.7 & 123,343 & 19.3 & 12,916 & 20.2 \\
\hline Middle & 320,401 & 50.6 & 32,355 & 51.1 & 314,205 & 49.2 & 32,491 & 50.9 \\
\hline High & 182,661 & 28.8 & 17,878 & 28.2 & 200,693 & 31.4 & 18,438 & 28.9 \\
\hline
\end{tabular}

Notes: The references (1:10) were matched on age and gender.

Missing data are not showed when representing less than $1 \%$. 
and corresponding 95\% confidence intervals for monthly and three-month incidence rates and rate ratios between cancer patients and the reference population of GP consultations, diagnostic investigations and hospital contacts. Robust variance estimation with clustering on patient level was used. To account for differences in follow-up time (relevant after diagnosis only), log-transformed risk time was included in the model with the regression parameter restricted to 1 . Censoring was thus done for all persons one year after the index date (date of diagnosis for cases) or when a person died, whichever came first. Separate analyses were performed for females and males, as gender-specific cancers represented $21 \%$ and $12 \%$ for women and men, respectively, and because it is known that men and women differ in their use of health care services [19]. Stata 12 was used for all analyses.

\section{Results}

The study included a total of 127,210 cancer patients and $1,272,100$ age and gender-matched controls. Among cancer patients, $49.8 \%$ were women and $50.2 \%$ were men; the age group 60-79 years represented $50.4 \%$ of the women and $60.6 \%$ of the men (Table 2). Table 2 shows that the characteristics of the cancer patients and the reference population were similar with respect to country of origin, marital status, education, labour market affiliation and income.

\section{Before the cancer diagnosis}

Figure 1 shows the monthly incidence rates for use of general practice, diagnostic investigations and hospital contacts for cancer patients and the reference population divided into women and men. GP consultation patterns changed from a modest rise in both genders five to six months before diagnosis to a steep rise that peaked around one month before diagnosis. The number of diagnostic examinations and hospital contacts started to rise three to four months before diagnosis with a steep rise setting in two months before diagnosis.
Figure 2 shows the proportions of persons being in contact with the healthcare system each month. The same pattern was seen as for the monthly incidence rates. In the month up to the diagnosis, approx. $60 \%$ of the cancer patients were seen in general practice compared with approx. $25 \%$ of the reference population. Even more pronounced differences were found for hospital services and diagnostic investigations. Throughout the whole period before the diagnosis, cancer patients used more health care services than the reference population and the six months preceding their diagnosis saw a steep rise in their consumption of health care services (Table 3).

\section{After the cancer diagnosis}

After having received their diagnosis, cancer patients used more health care services than their controls after adjusting for death. Figure 1 shows a marked use of hospital services in the year after the diagnosis; yet, the use of diagnostic investigations, in particular, fell rapidly. The increased monthly use of general practice flattened off around six months after diagnosis; and one year after diagnosis, the GP incidence rate was at the same level as for hospital services. Gender-specific consultation patterns were observed: men had more diagnostic investigations than women; whereas women had more hospital contacts than men. As seen in Figure 2, more than $80 \%$ of the cancer patients received hospital services in the month after their diagnosis compared with less than $10 \%$ of the controls. The proportion of cancer patients receiving each of the three types of health services remained more than $10 \%$ above that for the controls from two months before diagnosis until the end of the study period (Figure 2). Twelve months after diagnosis, the proportion of cancer patients being in contact with GPs on a monthly basis was approx. $40 \%$ - which is slightly higher than the proportion of patients having hospital contacts.

Cancer patients' propensity to be in contact with general practice remained high: they had $43-73 \%$ more GP
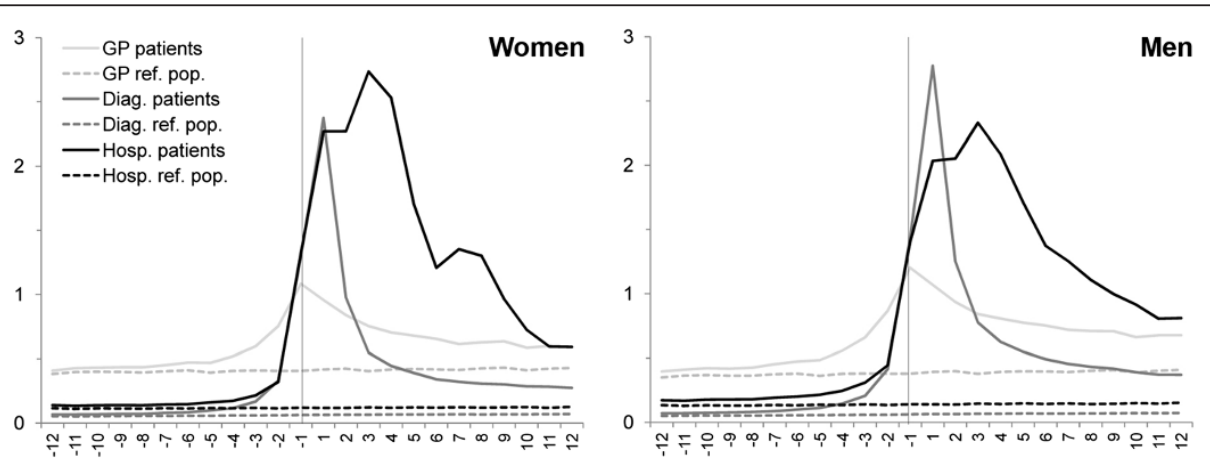

Figure 1 Incidence rates of health services received per month by cancer patients and reference population. Cancer patients ( $n=63,362$ women and 63,848 men). Reference population ( $n=633,620$ women and 638,480 men). Incidence rates were adjusted for time at risk. Vertical line indicates date of diagnosis. GP: General Practitioner; Diag.: Diagnostic investigations; Hosp.: Hospital contacts. 


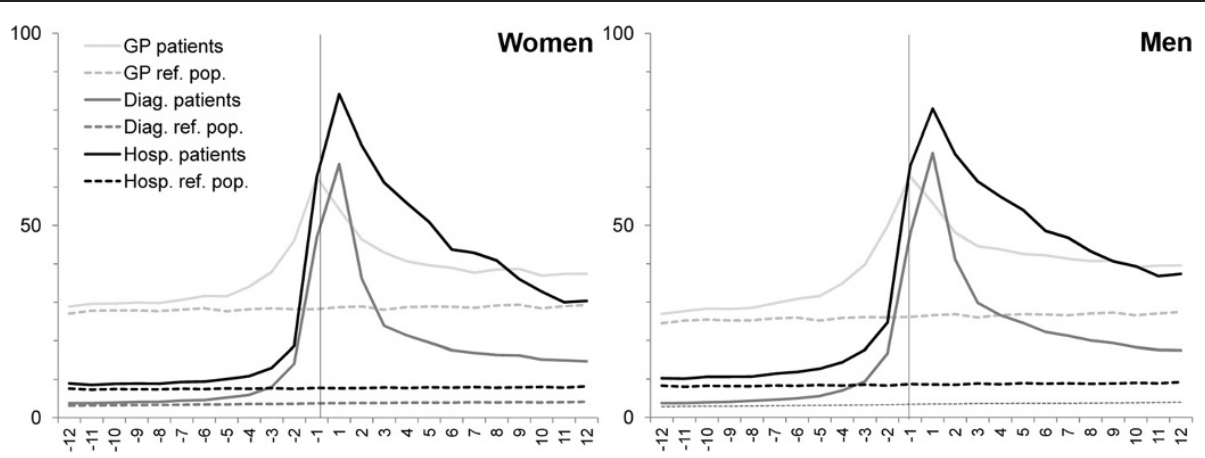

Figure 2 Percentage of cancer patients and reference population receiving health services per month. Cancer patients ( $n=63,362$ women and 63,848 men). Reference population ( $n=633,620$ women and 638,480 men). The proportion was adjusted for time at risk. Vertical line indicates date of diagnosis. GP: General Practitioner; Diag.: Diagnostic investigations; Hosp.: Hospital contacts.

Table 3 Incidence rate ratios for three-monthly use of general practice, diagnostic investigations and hospital services

\begin{tabular}{|c|c|c|c|c|c|}
\hline \multirow[b]{2}{*}{$\begin{array}{l}\text { Months from } \\
\text { diagnosis }\end{array}$} & \multirow[b]{2}{*}{ Services } & \multicolumn{2}{|c|}{ Women } & \multicolumn{2}{|r|}{ Men } \\
\hline & & IRR & $95 \% \mathrm{Cl}$ & IRR & $95 \% \mathrm{Cl}$ \\
\hline \multirow[t]{3}{*}{-12 to -10} & GP & 1.07 & $1.06-1.09$ & 1.13 & $1.12-1.15$ \\
\hline & Diagnostics & 1.24 & $1.20-1.28$ & 1.37 & $1.32-1.42$ \\
\hline & Hospital & 1.21 & $1.18-1.25$ & 1.31 & $1.28-1.35$ \\
\hline \multirow[t]{3}{*}{-9 to -7} & GP & 1.10 & $1.09-1.11$ & 1.17 & $1.16-1.19$ \\
\hline & Diagnostics & 1.32 & $1.28-1.36$ & 1.51 & $1.46-1.56$ \\
\hline & Hospital & 1.24 & $1.21-1.28$ & 1.38 & $1.35-1.42$ \\
\hline \multirow[t]{3}{*}{-6 to -4} & GP & 1.20 & $1.19-1.21$ & 1.34 & $1.33-1.36$ \\
\hline & Diagnostics & 1.66 & $1.61-1.71$ & 2.08 & $2.02-2.15$ \\
\hline & Hospital & 1.39 & $1.35-1.43$ & 1.64 & $1.60-1.68$ \\
\hline \multirow[t]{3}{*}{-3 to -1} & GP & 1.97 & $1.96-1.99$ & 2.38 & $2.36-2.39$ \\
\hline & Diagnostics & 9.61 & $9.47-9.76$ & 10.86 & $10.69-11.03$ \\
\hline & Hospital & 5.27 & $5.20-5.34$ & 5.16 & $5.09-5.23$ \\
\hline \multirow[t]{3}{*}{1 to 3} & GP & 2.12 & $2.10-2.14$ & 2.54 & $2.51-2.56$ \\
\hline & Diagnostics & 24.49 & $24.11-24.87$ & 29.20 & $28.73-29.67$ \\
\hline & Hospital & 19.91 & $19.68-20.14$ & 14.91 & $14.73-15.10$ \\
\hline \multirow[t]{3}{*}{4 to 6} & GP & 1.67 & $1.65-1.69$ & 2.05 & $2.02-2.07$ \\
\hline & Diagnostics & 6.25 & $6.12-6.38$ & 8.46 & $8.29-8.64$ \\
\hline & Hospital & 15.11 & $14.89-15.34$ & 12.08 & $11.90-12.27$ \\
\hline \multirow[t]{3}{*}{7 to 9} & $\mathrm{GP}$ & 1.50 & $1.48-1.52$ & 1.84 & $1.81-1.86$ \\
\hline & Diagnostics & 4.88 & $4.77-4.99$ & 6.42 & $6.27-6.57$ \\
\hline & Hospital & 9.98 & $9.80-10.16$ & 7.86 & $7.72-8.00$ \\
\hline \multirow[t]{3}{*}{10 to 12} & GP & 1.43 & $1.41-1.45$ & 1.73 & $1.70-1.75$ \\
\hline & Diagnostics & 4.37 & $4.27-4.48$ & 5.49 & $5.35-5.63$ \\
\hline & Hospital & 5.29 & $5.19-5.40$ & 5.82 & $5.71-5.94$ \\
\hline
\end{tabular}

Notes: IRR: Incidence rate ratio.

95\% Cl: 95\% Confidence interval.

GP: Face-to-face contacts with GPs in both daytime and out-of-hours.

Diagnostics: Diagnostic investigations including radiological investigations,

ultrasound, endoscopies and biopsies.

Hospital: Admissions and outpatient visits.

$\mathrm{n}$ (women) $=63,362$ cancer patients and 633,620 controls.

$\mathrm{n}$ (men) $=63,848$ cancer patients and 638,480 controls. consultations than the reference population 12 months after their diagnosis (Table 3); and this trend was even more pronounced for the use of diagnostic investigations and hospital services in the entire year after their diagnosis.

\section{Discussion \\ Main findings}

During the six months leading up to diagnosis, Danish cancer patients started using more primary and secondary health care services than the reference population. It came as no surprise that they were also much more prone to be in contact with the health care system in the aftercare period. The timing of the peaks of use of specific services indicates that for cancer patients as a group there is a time interval of some months between patients start attending general practice and the diagnosis.

\section{Strengths and weaknesses}

A strength of the present study is that we included a whole nation's incident cancer patients. This gives the present study a high degree of statistical precision. Another strength is that Danish health service registries are known to be valid $[23,24]$ because of the completeness of the registration of the Danish population and the continuity of registrations. The case-control study design was used to allow us to portray the baseline use of health care services of a reference population comparable with the cancer patients. The characteristics of the two populations were very much alike, which represents a third strength of the present study.

A weakness is that the date of diagnosis registered in the Danish Cancer Registry was systematically set to the first day in the month until 1 January 2004 where exact dates were introduced. Weaknesses in the validity that may arise because of changes in the definitions of variables over time, changes in coding or data entry procedures did not seem to affect the data as the control 
group's use of health care services remained stable during the study period. We included all types of cancer as the study overall illustrates how cancer is treated within a healthcare system. Thus, differences between specific cancer types and groups of patients will undoubtedly exist as shown in a recently published British survey including 41,299 cancer patients [8]. Further research should investigate this while including the time period of the consultations.

\section{Comparisons with other studies}

The aforementioned comprehensive British survey found that women were more likely than men to have had three or more GP consultations before hospital referral [8]. In the present study, we found a similar GP consultation pattern for both genders prior to diagnosis. Aside from the British survey [8], few existing studies have elucidated cancer patients' health service utilisation around the time of diagnosis and they all studied fewer than 500 patients. Moreover, their methods, focus and results differed which makes direct comparison difficult. A Dutch breast cancer study using GP records found that the percentage of women seeing their GP peaked at $90 \%$ in the first month after diagnosis [11]; contrary to this, our study showed that the percentage of cancer patients seeing their GP peaked in the month up to diagnosis at $63 \%$ for both men and women. A questionnaire study on delay in the diagnosis of colorectal cancer found that patients with a severe diagnostic delay had 2.5 consultations before the disease was diagnosed compared with 1.3 visits among those patients without severe delay [25], but no information about the timing of the visits was given. An interview study combined with data from hospital records of gastrointestinal cancer patients found a mean interval of 10 weeks between GP consultation and hospital referral [26], while we found a time interval of some months between the start of attending general practice and the start of treatment for cancer patients as a group. In our study, the first observed peak was in GP consultations, which is in accordance with previous studies which have found that cancer patients first contact their GPs [16,27-29].

\section{Implications for future research}

The present study fills major gaps in current knowledge about cancer patients' health service utilisation around the date of diagnosis and it hence identifies targets for organizational improvement and informs a future research agenda in this field. As previously suggested, the GPs seem to play an essential role in initiating cancer diagnosis $[27,30]$. One way of shortening the diagnostic interval could be to reduce the number of nonconclusive GP consultations by facilitating GPs access to fast and relevant diagnostic investigations, and by optimizing the hospital-based treatment phase. We saw that the health care utilisation pattern started changing six months prior to the cancer diagnosis. Future studies should elucidate this period with regards to e.g. different cancer types, the specific health services given by the different providers and demographic and socioeconomic patient characteristics. Such studies may help identify clinical and organizational inexpediencies, which is critical to optimal health care resource allocation and, not least, to patient pathway optimization.

The present study shows that 12 months after diagnosis, primary care was, indeed, involved in aftercare as was the hospital sector. The claimed lack of primary care involvement after discharge could perhaps originate in the lack of clear communication regarding task distribution as pointed out in a study on palliative home care for cancer patients [31]. Future research should investigate the organisation of aftercare in general and the transition between primary and secondary care in particular.

\section{Conclusions}

In cancer patients' pathway, the diagnostic window seems to open several months before the diagnosis is made as evidenced by a rising number of GP consultations, diagnostic examinations and hospital contacts. Whether this pattern of health care use is a sign of insufficient clinical or organisational knowledge, this study cannot answer. However, there seems to be a possibility of reducing the time from GP consultation to diagnostic investigations and treatment. During the period after diagnosis, the use of all health care services remained increased with hospital contacts being most prevalent. Contacts with general practice were also increased during the first year after diagnosis which documents the importance of coordination and planning of cancers patients' post-treatment course to improve survival. Future studies must be performed as detailed studies of specific health care services provided to specific types of cancer patients and their appropriateness in relation to effectiveness and equity in order to optimise the delivery of health services.

\section{Abbreviations \\ GP: General practitioner; ICD10: International Classification of Diseases version 10; ICD7: International Classification of Diseases version 7; CAT scan: Computed axial tomography scan; MRI scan: Magnetic resonance imaging scan; OECD: Organisation for Economic Co-operation and Development; ISCED: International Standard Classification of Education; IRR: Incidence rate ratio; 95\% Cl: 95\% confidence interval.}

\section{Competing interests}

The authors declare that they have no competing interests.

\section{Authors' contributions}

PV and KGC conceived the study. The data collection and analysis were done by KGC in consultation with KRF and PV. KGC performed the statistical analyses in consultation with MFG. KGC drafted the manuscript and all 
authors contributed to critically revising the paper. Finally, all authors read and approved the submitted manuscript.

\section{Authors' information}

Research Unit for General Practice and Research Centre for Cancer Diagnosis in Primary Care (CaP), Aarhus University, Bartholins Allé 2, 8000 Aarhus C, Denmark.

\section{Acknowledgements}

The study was funded by The Danish Cancer Society and the Novo Nordic Foundation. The funding sources were in no way involved in the research process.

Received: 8 March 2012 Accepted: 17 July 2012

Published: 28 July 2012

\section{References}

1. Foot C, Harrison T: How to improve cancer survival - Explaining England's relatively poor rates. London: The King's Fund; 2011.

2. Mitchell E, Macdonald S, Campbell NC, Weller D, Macleod U: Influences on pre-hospital delay in the diagnosis of colorectal cancer: a systematic review. Br J Cancer 2008, 98:60-70.

3. Torring ML, Frydenberg M, Hansen RP, Olesen F, Hamilton W, Vedsted P: Time to diagnosis and mortality in colorectal cancer: a cohort study in primary care. Br J Cancer 2011, 104:934-940.

4. Richards MA, Westcombe AM, Love SB, Littlejohns P, Ramirez AJ: Influence of delay on survival in patients with breast cancer: a systematic review. Lancet 1999, 353:1119-1126.

5. Albreht T, McKee M, Alexe DM, Coleman MP, Martin-Moreno JM: Making progress against cancer in Europe in 2008. Eur J Cancer 2008, 44:1451-1456.

6. Coleman MP, Forman D, Bryant H, Butler J, Rachet B, Maringe C, Nur U, Tracey E, Coory M, Hatcher J, et al: Cancer survival in Australia, Canada, Denmark, Norway, Sweden, and the UK, 1995-2007 (the International Cancer Benchmarking Partnership): an analysis of population-based cancer registry data. Lancet 2011, 377:127-138.

7. Jensen AR, Nellemann HM, Overgaard J: Tumor progression in waiting time for radiotherapy in head and neck cancer. Radiother Oncol 2007, 84:5-10.

8. Lyratzopoulos G, Neal RD, Barbiere JM, Rubin GP, Abel GA: Variation in number of general practitioner consultations before hospital referral for cancer: findings from the 2010 National Cancer Patient Experience Survey in England. Lancet Oncol 2012, 13:353-365.

9. Summerton N, Rigby AS, Mann S, Summerton AM: The general practitioner-patient consultation pattern as a tool for cancer diagnosis in general practice. Br J Gen Pract 2003, 53:50-52.

10. Olesen $\mathrm{F}$ : The pattern of attendance at general practice in the years before the diagnosis of cervical cancer. A case control study. Scand J Prim Health Care 1988, 6:199-203.

11. Roorda C, de Bock GH, van der Veen WJ, Lindeman A, Jansen L, van der Meer $\mathrm{K}$ : Role of the general practitioner during the active breast cancer treatment phase: an analysis of health care use. Support Care Cancer 2011, 20:705-714.

12. Dalsted RJ, Guassora AD, Thorsen T: Danish general practitioners only play a minor role in the coordination of cancer treatment. Dan Med Bull 2011, 58:A4222.

13. Mikkelsen $T H$, Soendergaard J, Jensen $A B$, Olesen F: Cancer surviving patients' rehabilitation - understanding failure through application of theoretical perspectives from Habermas. BMC Health Serv Res 2008, 8:122-135.

14. Lewis RA, Neal RD, Hendry M, France B, Williams NH, Russell D, Hughes DA, Russell I, Stuart NS, Weller D, et al: Patients' and healthcare professionals' views of cancer follow-up: systematic review. Br J Gen Pract 2009, 59:e248-e259.

15. Anvik T, Holtedahl KA, Mikalsen H: "When patients have cancer, they stop seeing me" - The role of the general practitioner in early follow-up of patients with cancer - A qualitative study. BMC Fam Pract 2006, 7.

16. Allgar VL, Neal RD: General practictioners' management of cancer in England: secondary analysis of data from the National Survey of NHS Patients-Cancer. Eur J Cancer Care (Engl) 2005, 14:409-416.
17. MacLennan R: Items of patient information which may be collected by registries. In Cancer Registration: Principles and Methods. 95th edition. Edited by Jensen OM, Parkin DM, MacLennan R, Muir CS, Skeet RG. Lyon: International Agency for Research on Cancer; 1991:43-63.

18. National Board of Health: [Common standards for the basic registration of hospital patients 2006]. Copenhagen: National Board of Health; 2005.

19. Juel K, Christensen K: Are men seeking medical advice too late? Contacts to general practitioners and hospital admissions in Denmark 2005. J Public Health (Oxf) 2008, 30:111-113.

20. Xue $X$, Hoover DR: Statistical methods in cancer epidemiological studies. Methods Mol Biol 2009, 471:239-272.

21. De Vos K, Zaidi MA: Equivalence scale sensitivity of poverty statistics for the member states of the European community. Rev Income Wealth 1997, 43:319-333.

22. UNESCO: International Standard Classification of Education ISCED. Montreal: UNESCO; 1997. ISBN 92-9189-035-9.

23. Olivarius NF, Hollnagel H, Krasnik A, Pedersen PA, Thorsen H: The Danish National Health Service Register. A tool for primary health care research. Dan Med Bull 1997, 44:449-453.

24. Sorensen HT, Sabroe S, Olsen J: A framework for evaluation of secondary data sources for epidemiological research. Int J Epidemiol 1996, 25:435-442.

25. Turunen MJ, Peltokallio P: Delay in the diagnosis of colorectal cancer. Ann Chir Gynaecol 1982, 71:277-282.

26. Macadam DB: A study in general practice of the symptoms and delay patterns in the diagnosis of gastrointestinal cancer. J R Coll Gen Pract 1979, 29:723-729.

27. Hansen RP, Olesen F, Sorensen HT, Sokolowski I, Sondergaard J: Socioeconomic patient characteristics predict delay in cancer diagnosis: a Danish cohort study. BMC Health Serv Res 2008, 8:49-59.

28. Demagny L, Holtedahl K, Bachimont J, Thorsen T, Letourmy A, Bungener M: General practitioners' role in cancer care: a French-Norwegian study. BMC Res Notes 2009, 2:200-206.

29. Campbell NC, Macleod U, Weller D: Primary care oncology: essential if high quality cancer care is to be achieved for all. Fam Pract 2002, 19:577-578.

30. Allgar $\mathrm{VL}, \mathrm{Neal} \mathrm{RD}$ : Delays in the diagnosis of six cancers: analysis of data from the National Survey of NHS Patients: Cancer. Br J Cancer 2005, 92:1959-1970.

31. Brogaard $T$, Jensen AB, Sokolowski I, Olesen F, Neergaard MA: Who is the key worker in palliative home care? Scand J Prim Health Care 2011, 29:150-156.

doi:10.1186/1472-6963-12-224

Cite this article as: Christensen et al:: Use of general practice, diagnostic investigations and hospital services before and after cancer diagnosis a population-based nationwide registry study of 127,000 incident adult cancer patients. BMC Health Services Research 2012 12:224.

\section{Submit your next manuscript to BioMed Central and take full advantage of:}

- Convenient online submission

- Thorough peer review

- No space constraints or color figure charges

- Immediate publication on acceptance

- Inclusion in PubMed, CAS, Scopus and Google Scholar

- Research which is freely available for redistribution 